\title{
Ultrasound stimulation increases proliferation of MC3T3-E1 preosteoblast-like cells
}

Amit Katiyar $^{1 *}$, Randall L Duncan ${ }^{1,2}$ and Kausik Sarkar ${ }^{1,3}$

\begin{abstract}
Background: Mechanical stimulation of bone increases bone mass and fracture healing, at least in part, through increases in proliferation of osteoblasts and osteoprogenitor cells. Researchers have previously performed in vitro studies of ultrasound-induced osteoblast proliferation but mostly used fixed ultrasound settings and have reported widely varying and inconclusive results. Here we critically investigated the effects of the excitation parameters of low-intensity pulsed ultrasound (LIPUS) stimulation on proliferation of MC3T3-E1 preosteoblastic cells in monolayer cultures.
\end{abstract}

Methods: We used a custom-designed ultrasound exposure system to vary the key ultrasound parameters -intensity, frequency and excitation duration. MC3T3-E1 cells were seeded in 12-well cell culture plates. Unless otherwise specified, treated cells, in groups of three, were excited twice for $10 \mathrm{~min}$ with an interval of $24 \mathrm{~h}$ in between after cell seeding. Proliferation rates of these cells were determined using BrdU and MTS assays $24 \mathrm{~h}$ after the last LIPUS excitation. All data are presented as the mean \pm standard error. The statistical significance was determined using Student's two-sample two-tailed $t$ tests.

Results: Using discrete LIPUS intensities ranging from 1 to $500 \mathrm{~mW} / \mathrm{cm}^{2}$ (SATA, spatial average-temporal average), we found that approximately $75 \mathrm{~mW} / \mathrm{cm}^{2}$ produced the greatest increase in osteoblast proliferation. Ultrasound exposures at higher intensity (approximately $465 \mathrm{~mW} / \mathrm{cm}^{2}$ ) significantly reduced proliferation in MC3T3-E1 cells, suggesting that high-intensity pulsed ultrasound may increase apoptosis or loss of adhesion in these cells.

Variation in LIPUS frequency from $0.5 \mathrm{MHz}$ to $5 \mathrm{MHz}$ indicated that osteoblast proliferation rate was not frequency dependent. We found no difference in the increase in proliferation rate if LIPUS was applied for $30 \mathrm{~min} /$ day or $10 \mathrm{~min} /$ day, indicating a habituation response.

Conclusion: This study concludes that a short-term stimulation with optimum intensity can enhance proliferation of preosteoblast-like bone cells that plays an important role in bone formation and accelerated fracture healing, also suggesting a possible therapeutic treatment for reduced bone mass.

Keywords: Osteoblast, Proliferation, Ultrasound, Mechanical stimulation, LIPUS

\section{Background}

Bone fracture healing is a complex physiological process that sequentially involves initial inflammation, soft and hard-callus formation and finally bone repair and remodeling [1]. Every year, millions of fractures are reported worldwide-according to the World Health Organization, in 2000, approximately 9.0 million osteoporotic fractures were reported worldwide, half of them in America and Europe. Even with the state of the art clinical treatments,

\footnotetext{
* Correspondence: akatiyar@udel.edu

'Department of Mechanical Engineering, University of Delaware, Newark, DE 19716, USA

Full list of author information is available at the end of the article
}

$5 \%-10 \%$ of bone fractures in the USA fail (nonunion) or take more than usual time (delayed union) to heal [2]. The extended treatment might require surgical intervention for possible bone-grafting and/or internal fixation.

Mechanical forces are required for skeletal homeostasis $[3,4]$. LIPUS is a nonthermal and nondestructive source of mechanical energy (i.e. intensity $=5-100 \mathrm{~mW} / \mathrm{cm}^{2}$ ) [5]. Application of low-intensity pulsed ultrasound (LIPUS) has been approved for treatment of fresh as well as nonunion fractures by the Food and Drug Administration. LIPUS resulted in a significant reduction in the overall fracture healing time in several animal models $[6,7]$ and 
clinical trials [8-11]. LIPUS can produce micromechanical strains in tissues which, in turn, can trigger several cellular responses [12]. However, they are not completely understood [13-15]. Previous researchers investigated the effects of LIPUS on various cellular activities such as cell proliferation [16], cell differentiation [5], extracellular collagen synthesis, protein and factor synthesis, gene expression, and cytosolic calcium levels [16].

To date, investigations of LIPUS stimulation of bones concentrated on the bone-forming cells, the osteoblast $[17,18]$. In vitro studies of ultrasound-induced osteoblast proliferation, however, have reported widely varying results. Doan et al. [19] found significant but unevenly distributed increase in human mandibular osteoblast cell proliferation (32\% at $5 \mathrm{~mW} / \mathrm{cm}^{2}$ spatial average (SA), $5 \%$ at $15 \mathrm{~mW} / \mathrm{cm}^{2} \mathrm{SA}, 35 \%$ at $30 \mathrm{~mW} / \mathrm{cm}^{2} \mathrm{SA}$, and $18 \%$ at $50 \mathrm{~mW} / \mathrm{cm}^{2} \mathrm{SA}$ ) using a near-field continuous ultrasound exposures at $45 \mathrm{kHz}$. At $1 \mathrm{MHz}$ pulsed ultrasound excitation, increased cell proliferation was observed in the same study but only at relatively higher intensities ( $47 \%$ at $0.7 \mathrm{~W} / \mathrm{cm}^{2}$ spatial average-pulse average (SAPA) and $37 \%$ at $1 \mathrm{~W} / \mathrm{cm}^{2} \mathrm{SAPA}$ ). Hayton et al. [20] found approximately $10 \%$ rise of proliferation in human osteoblast-like cells Saos-2 due to a 40-min excitation of standard LIPUS exposure-1.5 MHz frequency, $1 \mathrm{kHz}$ PRF (pulse repetition frequency), $200 \mu$ s pulse duration and $30 \mathrm{~mW} / \mathrm{cm}^{2}$ intensity. In contrast, Suzuki et al. $[5,21]$ showed that there is no effect on cell proliferation for a near-field and 20-min standard LIPUS exposure to rat osteoblast-like cells ROS 17/2.8. Most recently, Kang et al. [22] studied the effects of $20 \mathrm{~min}$ a day stimulation by a low-intensity ultrasound $(1 \mathrm{MHz}, 30 \mathrm{~mW} / \mathrm{cm} 2 \mathrm{con}$ tinuous sine wave) in combination with cyclic vibratory strain $(1 \mathrm{~Hz}, 10 \%$ strain) on MC3T3-E1 cells in a 3D scaffold. The stimulation did not change the cell proliferation over a period of 10 days, but significantly up-regulated several gene expressions-COL-I, OC, RUNX2, and OSXindicating accelerated differentiation.

It is clear that LIPUS parameters for peak proliferation vary and the effects on osteoblast or osteoblast-like cells are not always the same. There is a need for a systematic study of the LIPUS effects varying the parameters of excitation such as intensity, frequency, and waveform. The objective of this study was to determine the effects of near-field LIPUS-induced mechanical stimulation on osteoblast cell proliferation in a monolayer culture and to understand its dependence on key ultrasound parameters: intensity, frequency, and the excitation period.

\section{Methods}

\section{Cell culture}

The MC3T3-E1 cells (passages 20-27), a preosteoblastic cell line, were cultured in $\alpha$-minimal essential medium (Sigma Chemical, St. Louis, MO, USA) containing 10\% fetal bovine serum (Gibco, New York, NY, USA), 100 units/ml penicillin G (Sigma) and $100 \mu \mathrm{g} / \mathrm{ml}$ streptomycin (Sigma). Cells were cultured in a humidified incubator at $37^{\circ} \mathrm{C}$ with $95 \%$ air and $5 \% \mathrm{CO}_{2}$ and subcultured every $72 \mathrm{~h}$.

\section{Ultrasound excitation}

In previous studies, modified clinical devices have been used to produce LIPUS $[16,18,19,23,24]$. However, to obtain better control on the characteristic parameters of US, we used a custom-designed ultrasound exposure system. The arrangement of electronic instruments for ultrasound exposure is shown in Figure 1a. A programmable function generator (33250A, Agilent, Palo Alto, CA, USA) produced standard $200 \mu$ s long pulses (sinusoidal waves) at $1 \mathrm{kHz}$ PRF. The transmit signal was amplified by a broadband $55 \mathrm{~dB}$ laboratory RF power amplifier (model A-150; ENI, Rochester, NY, USA) and then supplied to a singleelement unfocused immersion transducer (part number A306S, GE Panametrics, Waltham, MA, USA). The transducer had an outside diameter of $16 \mathrm{~mm}$ and a center frequency of $2.5 \mathrm{MHz}$. For frequency variation study, we used transducers with different center frequencies.

The ultrasound transducer and an XYZ positioning stage (Newport Corp., CA, USA) were sterilized with $75 \%$ of ethanol and kept under ultraviolet light for at least $2 \mathrm{~h}$ before the experiments. Based on the diameter of the transducer (head area $2.01 \mathrm{~cm}^{2}$ ), we found 12-well cell culture plates (growth area $3.80 \mathrm{~cm}^{2}$ ) appropriate for our experiments. MC3T3-E1 cells were seeded on the bottom of the 12-well plate with $1.5 \mathrm{~mL}$ of cell culture medium. The transducer head was positioned vertically over the culture well, just touching the surface of the medium (Figure 1b). In this configuration, the distance between the transducer head and the bottom of the dish was approximately $4 \pm 0.5 \mathrm{~mm}$ (determined from the XYZ positioning as well as the cross-section area of the cell and the volume of the medium) and kept constant for all the experiments. Note that the cells are in the near field, as in several other investigations $[19,21]$ and, therefore, are subjected to a spatially nonuniform field. However, the setup has the advantage of direct stimulation by the immersed transducer unimpeded by an intervening medium which would otherwise attenuate the signal. Note that several animal and clinical trials of therapeutic ultrasound involved near-field stimulation by transducers in direct contact with the skin $[8,9,11]$. Li et al. [24] specifically determined the optimum intensity for far-field stimulations and found it to be comparable to the near-field values quoted in the literature. For the stimulation used here, the proper spatial averages are computed using the relations described in the Appendix.

MC3T3-E1 cells at 50\%-60\% confluence $\left(2.28 \times 10^{4}\right.$ cells per well $\approx 6 \times 10^{3}$ cells $/ \mathrm{cm}^{2}$ ) were seeded in 12 -well cell culture plates. We experimentally verified that these 


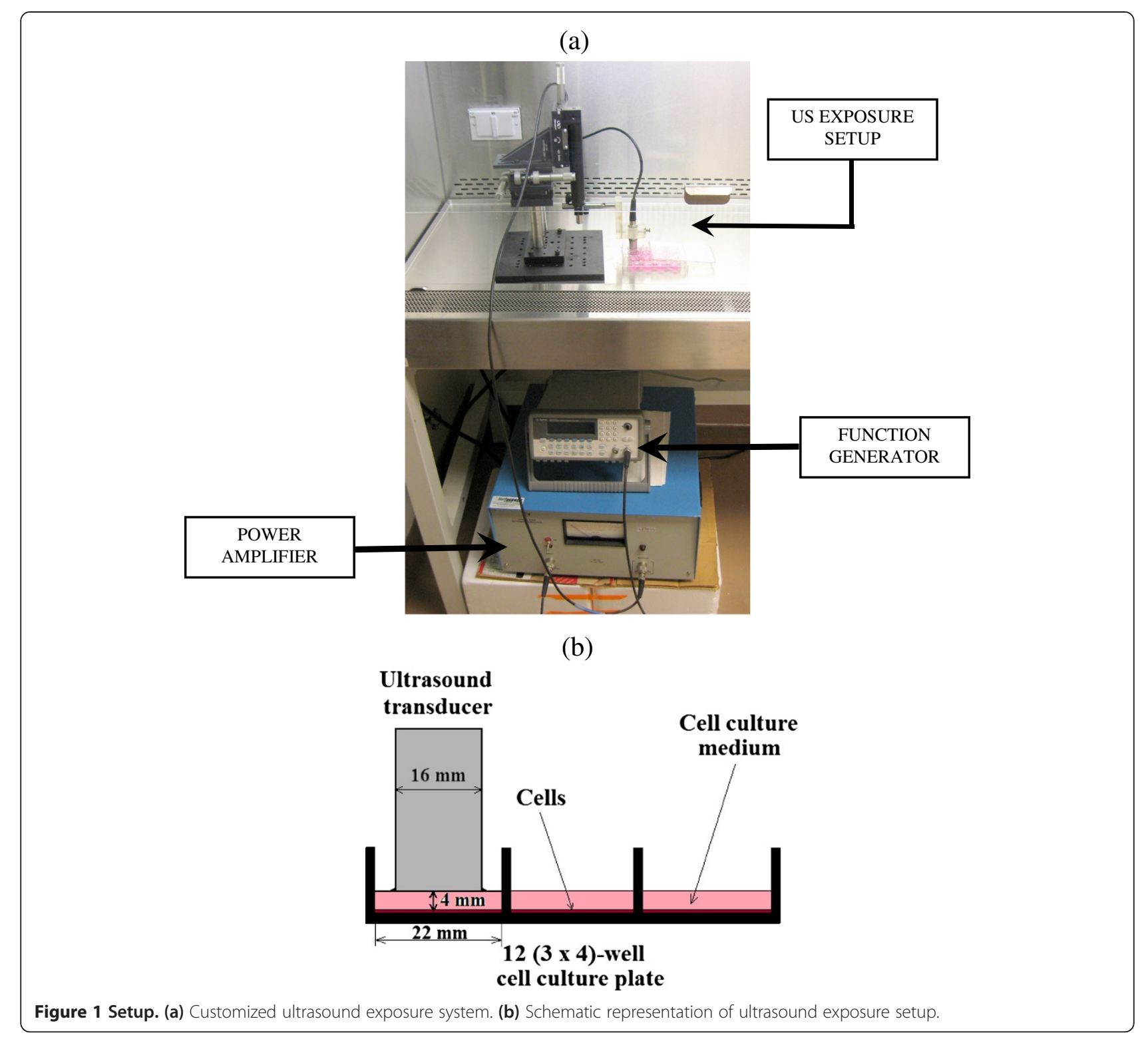

cells remain in linear phase of proliferation up to approximately $4 \times 10^{4}$ cells per well. Cells received their first US stimulation $24 \mathrm{~h}$ after seeding. Unless otherwise mentioned, stimulation was given twice for $10 \mathrm{~min}$ and at an interval of $24 \mathrm{~h}$. The control group underwent the same experimental treatment with the ultrasound powered off.

We note that there is a possibility of indirect transfer of mechanical energy of ultrasound to the neighboring wells [25]. We investigated the secondary ultrasound stimulation in neighboring wells and found it less than $1 \%$ to that transferred directly. We note that our setup for ultrasound stimulation has been frequently used for studying its cellular effects and release properties of drug bearing vesicles. Recent studies have indicated that in this setup, reflections from the air-water interface create a standing wave pattern giving rise to a spatially varying acoustic field $[20,21]$. However, note that unlike in a suspension of drug bearing particles, ours is a monolayer of cells with dimension which is much smaller than the wavelength. Therefore, the variation of excitation between cells is negligibly small, and the current setup is adequate for our purpose.

\section{Determination of cell proliferation \\ BrdU assay}

The BrdU ELISA (Amersham Cell Proliferation Biotrak ELISA system, version 2, GE Healthcare Bio-Sciences Corp., Piscataway, NJ, USA) is based on incorporation of 5-bromo-2'-deoxyuridine (BrdU) during DNA synthesis in proliferating cells. To quantify the cell proliferation (24 h after second US stimulation), BrdU labeling reagent 
diluted with cell culture medium $(0.4 \mathrm{ml}$ of 1:1,000 v/v) was added to each well of 12-well plate and the cells were reincubated for $2 \mathrm{~h}$ in a humidified incubator at $37^{\circ} \mathrm{C}$ with 95\% air and $5 \% \mathrm{CO}_{2}$. During the labeling period, BrdU is incorporated in place of thymidine into the DNA of proliferating cells. The BrdU labeling reagent was then removed from the well, and $0.4 \mathrm{~mL}$ of fixative solution (for cell fixation and DNA denaturation) supplied in the kit was added to each well, and the cells were incubated for an additional $30 \mathrm{~min}$ at room temperature (RT). The denaturation of the DNA is necessary to improve the accessibility of the incorporated BrdU for detection by the antibody. The fixative solution was then removed and $0.4 \mathrm{~mL}$ of 1:10 diluted blocking buffer (also supplied in the kit to block the remaining binding surface and prevent any nonspecific binding of the antibodies) was added to each well. Following incubation at room temperature for $30 \mathrm{~min}$, the blocking buffer was removed and $0.4 \mathrm{~mL}$ of 1:100 of diluted peroxidase-labeled anti-BrdU (monoclonal antibody from mouse cells conjugated to peroxidase, lyophilized, and stabilized) working solution was added. The peroxidase-labeled anti-BrdU solution is diluted with supplied antibody dilution solution. Cells were incubated in this solution at room temperature for $90 \mathrm{~min}$. The peroxidase-labeled anti-BrdU binds to the BrdU, which is incorporated in newly synthesized cellular DNA. The antiBrdU working solution was then removed, and the cells were washed with $1 \mathrm{ml}$ of 1:10 diluted wash buffer solution (phosphate buffer saline (PBS), 10× concentrate) three times at room temperature. Room temperatureequilibrated 3,3'5,5-tetramethylbenzidine (TMB) substrate solution $(0.4 \mathrm{~mL})$ in $15 \%(v / v)$ dimethyl sulfoxide (DMSO) was then added to each well. The immune complex formed after adding the peroxidase-labeled anti-BrdU reacts with TMB substrate. After approximately $10 \mathrm{~min}$, a light blue color solution is obtained and the reaction was then stopped by adding $100 \mu \mathrm{L}$ of $2 \mathrm{M} \mathrm{H}_{2} \mathrm{SO}_{4}$ solution to each well. The optical density (absorbance) of $150 \mu \mathrm{L}$ of resultant yellowish color solution was read at $450 \mathrm{~nm}$ in a 96-well microplate spectrophotometer. The absorbance values correlate directly to the amount of DNA synthesis and thereby to the number of proliferating cells in culture.

\section{MTS assay}

To corroborate the BrdU data, osteoblast cell number was also determined using [3-(4,5-dimethylthiazol-2-yl)-5(3-caroxymethoxyphenyl)-2-(4-sulfophenyl)-2H-tetrazolium (MTS) assay (CellTiter 96 Aqueous, Promega, Madison, WI, USA). This assay is colorimetric based on the reduction of the MTS tetrazolium by the living cells to a formazan product. The absorbance of the formazan product is measured at $490 \mathrm{~nm}$ and the generation of this product is directly proportional to the cell mass. In this assay, $80 \mu \mathrm{L}$ of the MTS solution was diluted into $0.4 \mathrm{ml}$ of cell culture medium and added to each well. The cell culture plate was incubated $37^{\circ} \mathrm{C}$ for $2 \mathrm{~h}$ in a humidified $5 \% \mathrm{CO}_{2}$ atmosphere. The absorbance was recorded at $490 \mathrm{~nm}$ using a 96-well plate reader.

In this study, each single experiment was repeated at least three times on three different passages of MC3T3E1. All data are presented as the mean \pm standard error (SE). The statistical significance was determined using Student's two-sample two-tailed $t$ tests. Values of $p<0.05$ were considered to be statistically significant.

\section{Results}

MC3T3-E1 osteoblasts responded to LIPUS with increase in cell proliferation, and the details are provided in the following subsections.

\section{Intensity dependence of osteoblast proliferation}

To determine the peak proliferative response, the ultrasound intensity was first varied over the range of 1 to $500 \mathrm{~mW} / \mathrm{cm}^{2}$ (SATA). The exposure time was set at $10 \mathrm{~min}$ and all other parameters (frequency $=1.5 \mathrm{MHz}$, $\mathrm{PRF}=1 \mathrm{kHz}$, pulse duration $=200 \mu \mathrm{s}$ ) were kept the same. We varied the input electrical signal to transducer by a factor of 2 and 2.5, which increased the ultrasound intensity by a factor of 4 and 6.25 respectively (1.16, $4.64,18.57,74.27$, and $\left.464.18 \mathrm{~mW} / \mathrm{cm}^{2}\right)$. Figure 2 shows the effect of ultrasound excitation at different intensities on osteoblast cell proliferation. The BrdU assay shows that the cell proliferation increased approximately $20 \%$, $30 \%, 36 \%$, and $49 \%$ for the four lower intensities, respectively. At the higher intensity of approximately $465 \mathrm{~mW} / \mathrm{cm}^{2}$, the proliferation decreased by approximately $6 \%$, showing an inhibitory effect on osteoblast cell growth. Some cells were also found detached from the base of the cell culture plate after the excitation at this higher intensity.

The BrdU measurements were validated with an MTS assay. As shown in Figure 2, the increase in cell proliferation was approximately $16 \%, 25 \%, 36 \%$, and $52 \%$ for the four lower intensities respectively. Further, stimulation at the higher intensity of approximately $465 \mathrm{~mW} / \mathrm{cm}^{2}$ was detrimental to cell viability with a proliferation decrease of approximately $21 \%$. These results obtained by an independent assay are similar to those obtained by the BrdU assay.

Microscopic images of MC3T3-E1 preosteoblastic cells after two 10-min US excitations at 24-h interval and at different ultrasound intensities are shown in Figure 3. These images were taken at the central portion of the respective wells where maximum ultrasound intensity was delivered. Though the increase in cell number due to US stimulation over control group is not always visually distinct, Figure 3 shows that the cell count increased approximately $19 \%, 32 \%, 39 \%$, and $53 \%$ for the four lower 


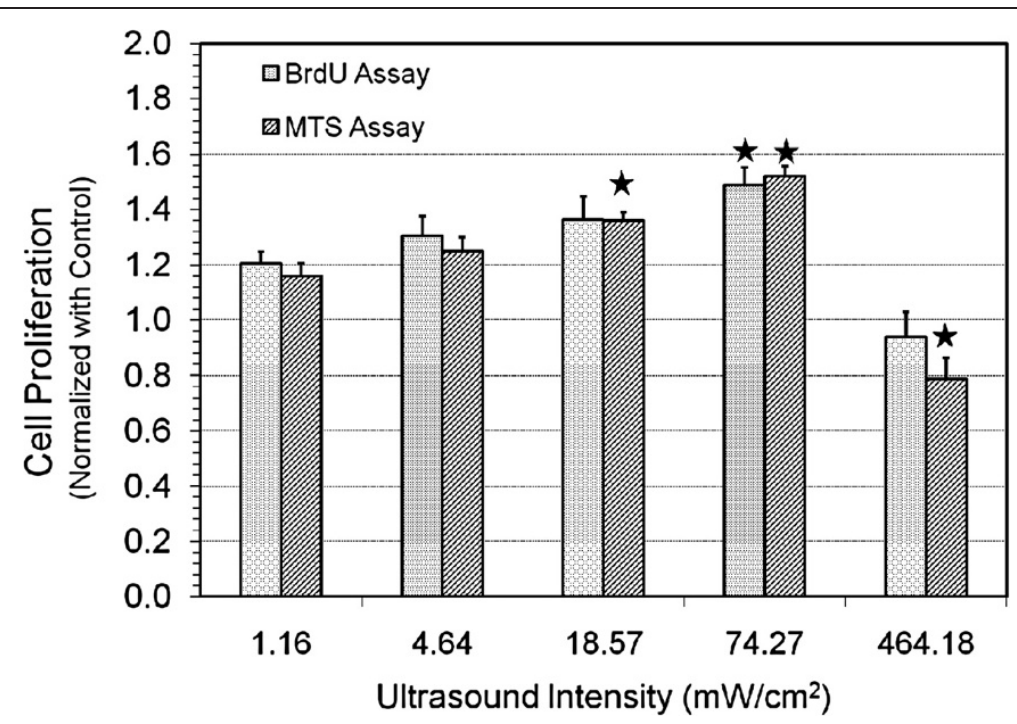

Figure 2 Change in normalized proliferation of MC3T3-E1 cells with ultrasound intensity. Change in proliferation of ultrasound stimulated MC3T3-E1 cells (normalized with control) at different ultrasound intensities (SATA) with frequency $=1.5 \mathrm{MHz}, \mathrm{PRF}=1 \mathrm{kHz}$, pulse duration $=200 \mu \mathrm{s}$ and exposure time $=10 \mathrm{~min}$. Values significantly different from control group have been indicated by filled stars for $p<0.05$.
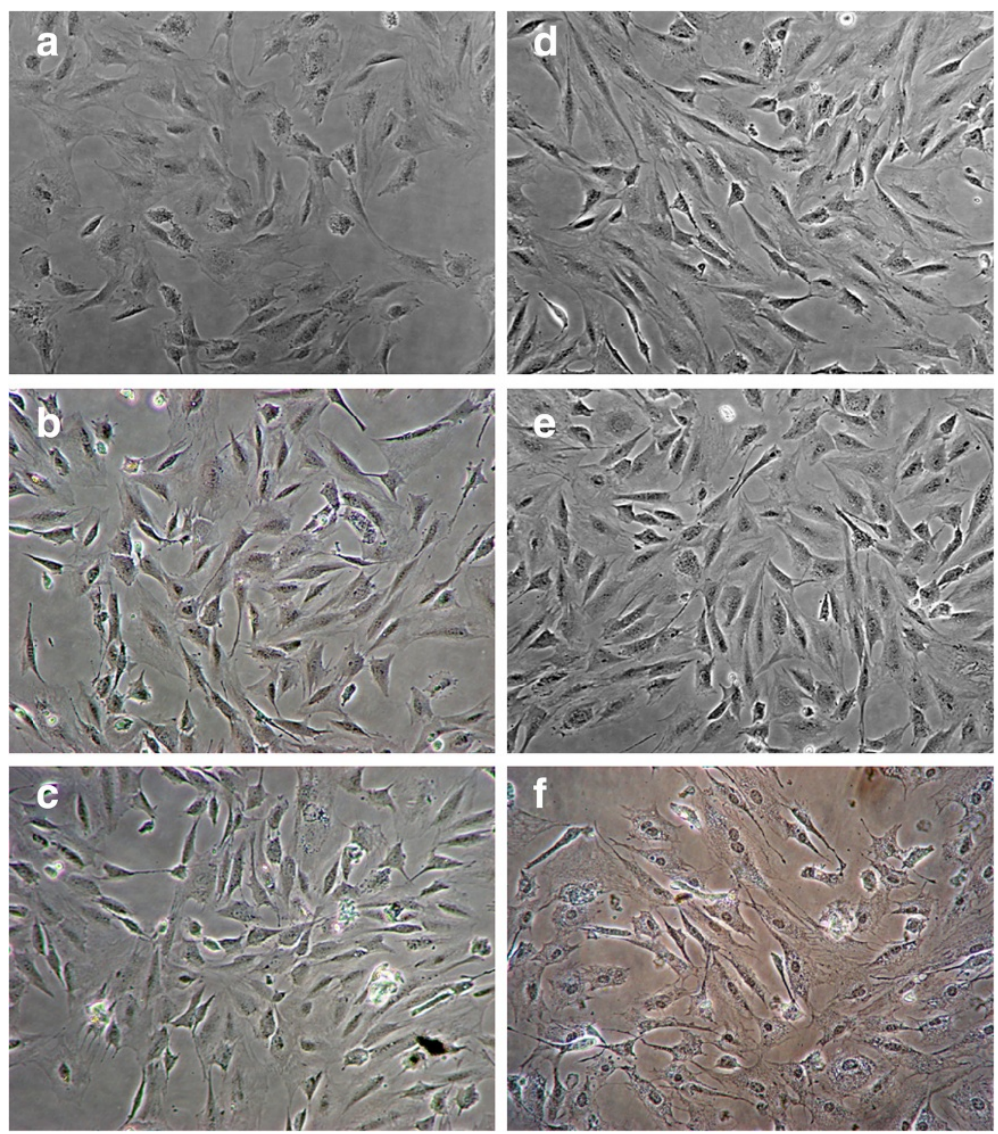

Figure 3 Microscopic images of MC3T3-E1 cells at the end of LIPUS stimulation. Microscopic images of cell growth after two 10-min ultrasound excitations at 24-h interval and at following ultrasound intensities (a) control, (b) $1.16 \mathrm{~mW} / \mathrm{cm}^{2}$, (c) $4.64 \mathrm{~mW} / \mathrm{cm}^{2}$, (d) $18.57 \mathrm{~mW} / \mathrm{cm}^{2}$, (e) $74.27 \mathrm{~mW} / \mathrm{cm}^{2}$, and (f) $464.18 \mathrm{~mW} / \mathrm{cm}^{2}$. Magnification $\times 20$. 
intensities, respectively. For the higher LIPUS intensity of approximately $465 \mathrm{~mW} / \mathrm{cm}^{2}$, cells distinctly look compressed and damaged.

\section{Frequency dependence of proliferation in MC3T3-E1 cells} Once the optimum intensity was identified, effects of excitation frequency were investigated over frequencies ranging from 0.5 to $5 \mathrm{MHz}$ at the optimal intensity $\left(75 \mathrm{~mW} / \mathrm{cm}^{2}\right)$ with a 10-min exposure time. In this experiment, we ensured that the pulse duration $(200 \mu \mathrm{s})$ and PRF $(1 \mathrm{kHz})$ remained the same by changing the number of cycles while changing the frequency. Figure 4 shows that the ultrasound stimulation increased osteoblast cell proliferation at all three frequencies. However, there is no statistically significant difference in proliferation at different frequencies.

\section{Optimum ultrasound excitation period for peak proliferative response}

In several previous in vitro studies, researchers have explored the effects of ultrasound application from a few seconds to several hours $[16,20,26,27]$. To determine if osteoblast proliferation was dependent on the excitation period, we varied it for $5,10,20$, and $30 \mathrm{~min}$. Figure 5 shows that the ultrasound stimulation increased cell proliferation for each excitation period tested. However, only $10 \mathrm{~min}$ and more exposure periods show statistically significant increase over the control group. There was no statistically significant difference among the LIPUS excited groups at different exposure times of 10, 20, and $30 \mathrm{~min}$.

\section{Discussion}

Mechanical stimuli play an important role in the development and maintenance of healthy skeleton. Increased

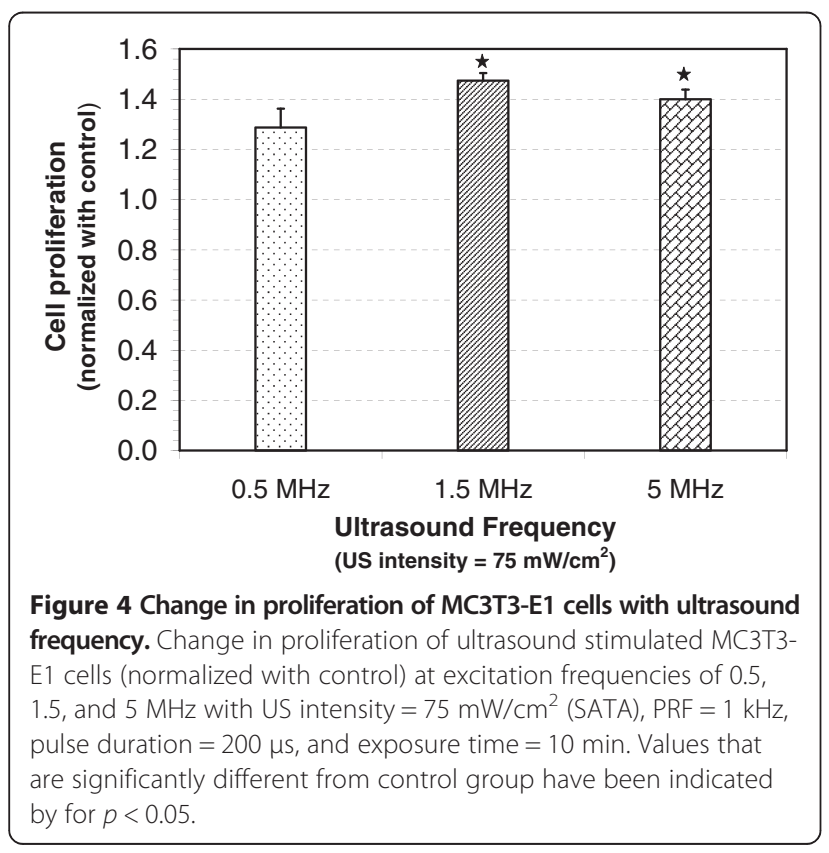

mechanical loading on bone enhances bone formation and suppresses bone resorption to increase bone mass $[28,29]$. Bone cells sense the mechanical forces and produce biochemical signals to bring the changes in their microenvironment. For example, mechanical loading generates microstrains and causes fluid flow through lacunar and canalicular spaces of the bone. The resulting fluid shear stress can stimulate osteoblast proliferation [30], contributing to the increase in bone mass. Ultrasound is a source of noninvasive mechanical stimulation that can induce acoustic streaming (unidirectional movement in an ultrasonic pressure field), acoustic microstreaming (rapidly rotating small-scale fluid motion around oscillating bubbles), and cavitation (formation of tiny gas bubbles in the tissues as the result of ultrasound vibration) [31]. Because of the low intensity and thereby low mechanical index $(0.078$ for the intensity of $75 \mathrm{~mW} /$ $\mathrm{cm}^{2}$ and 0.488 at $465 \mathrm{~mW} / \mathrm{cm}^{2}$ ) of the stimulation used, we do not expect any cavitation here [15]. Although we did not try to detect cavitation directly in the setup, the excitation in the range of intensities used here did not generate cavitation in water. Utmost care has been taken to avoid the formation of bubbles in the medium. In any event, different mechanical effects caused by the ultrasound further cause fluid flow in the extracellular space [12] and result in deformation and strain to osteoblasts. Thus, osteoblasts should respond to LIPUS in part due to the same mechanisms that are present in case of shear forces from fluid flow.

Using BrdU and MTS assays, we found enhanced proliferation at different LIPUS intensities with maximum effect at approximately $75 \mathrm{~mW} / \mathrm{cm}^{2}$. This optimum LIPUS intensity is of the same order reported previously in literature. Reher et al. [23] found the optimum intensity to be $100 \mathrm{~mW} / \mathrm{cm}^{2}$ SAPA for osteoblastic cell lines with a $200-\mu$ s pulse at $1 \mathrm{MHz}$ frequency, whereas intensities higher than approximately $750 \mathrm{~mW} / \mathrm{cm}^{2}$ led to the inhibition of collagen and noncollagenous proteins. $\mathrm{Li}$ et al. [24] found an optimum intensity of $600 \mathrm{~mW} / \mathrm{cm}^{2}$ SATP or $120 \mathrm{~mW} / \mathrm{cm}^{2}$ (SATA) for osteoblast growth at $100 \mathrm{~Hz}$ PRF, 1:4 duty cycle (2 ms burst period), $1 \mathrm{MHz}$ US frequency, $15 \mathrm{~min}$ exposure time, and $24 \mathrm{~cm}$ exposure distance. We also found that the US exposure at higher intensities (approximately $465 \mathrm{~mW} / \mathrm{cm}^{2} \mathrm{SAPA}$ ) proved detrimental to osteoblasts. In a far-field LIPUS exposure study, Li et al. [24] also reported complete inhibition of cell proliferation at $480 \mathrm{~mW} / \mathrm{cm}^{2}$ SAPA. Highintensity US exposures have been shown to suppress bone formation in animal models as well [32].

In an attempt to determine the optimum stimulation frequency, we investigated three different frequencies: $0.5,1.5$, and $5 \mathrm{MHz}$ but found no statistically significant difference in osteoblast cell proliferation between them. We also examined the duration of US stimulation to 


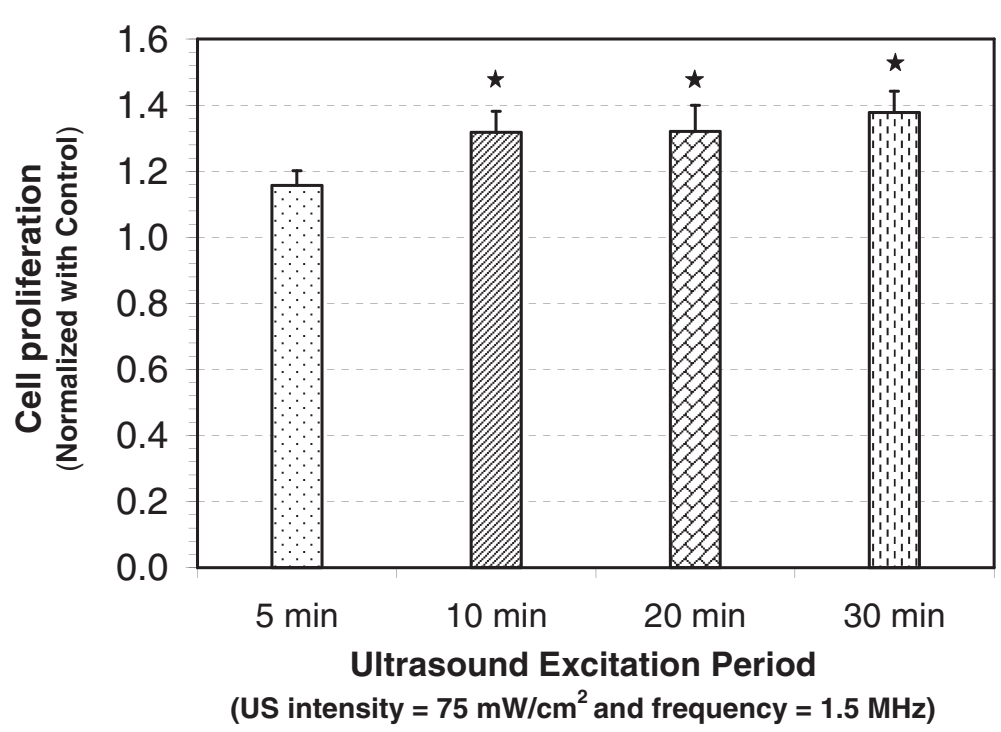

Figure 5 Change in proliferation of MC3T3-E1 cells ultrasound exposure period. Change in proliferation of ultrasound-stimulated MC3T3-E1 cells (normalized with control) at different ultrasound exposure periods of 5, 10, 20, and 30 min with ultrasound intensity $=75 \mathrm{~mW} / \mathrm{cm}^{2}$ (SATA), frequency $=1.5 \mathrm{MHz}, \mathrm{PRF}=1 \mathrm{kHz}$, and pulse duration = $200 \mu \mathrm{s}$. Values significantly different from control group have been indicated by filled star for $p<0.05$.

yield peak cellular proliferation. At the optimum US intensity, we found that longer stimulation of $30 \mathrm{~min}$ a day was not significantly different from a shorter stimulation of $10 \mathrm{~min}$ a day, indicating a habituation response. It has been shown that bone mass increases if loading is applied in intermittent bouts, as bone and osteoblasts become less sensitive to longer mechanical stimulation [33].

How ultrasound alters cell function remains uncertain. Studies using rat bone marrow stromal cells, primary osteoblasts, or intact bone have shown that differentiation markers are increased with $2-30 \mathrm{~mW} / \mathrm{cm}^{2}$ LIPUS and that this increase corresponds to the increases in focal adhesion kinase (FAK), $\beta$-catenin activation, and MAP kinases [34-37]. When the $\alpha_{5} \beta_{1}$ integrins were blocked in primary osteoblasts, LIPUS failed to increase PI3 kinase and $\beta$-catenin activity, suggesting that integrins could be the primary sensing molecule for LIPUS [37]. However, several studies in mechanotransduction in bone suggest that other signaling pathways could be sensitive to LIPUS to increase proliferation. Release of ATP and the resultant purinergic signaling increases proliferation, initiates differentiation, and can induce cell death in numerous cells types [38]. We have shown that ATP is released from osteoblasts in response to fluid shear [39] and cyclic hydrostatic pressure [40] and that activation of purinergic receptors is required for mechanically induced bone formation [41]. This release of ATP is mediated through activation of mechanosensitive and voltage-sensitive calcium channels in osteoblasts [39] that could also be responsive to LIPUS. For osteoblast cells, intracellular and extracellular calcium stores and their transport between these stores can play an important role in their response to mechanical stimuli such as LIPUS. Voltage-sensitive calcium channels (VSCCs) have been reported to be the key regulators of intracellular calcium signaling in osteoblasts [39]. In future studies, we plan to investigate possible roles of ultrasound-induced calcium transport in enhanced osteoblast cell proliferation.

\section{Conclusions}

This study demonstrated that the application of near-field LIPUS stimulation is a viable method to enhance osteoblast cell proliferation in monolayer culture. It also supports the possibility that US-induced increased osteoblast proliferation plays an important role in bone formation and accelerated fracture healing. Our findings indicate the need to better define the optimum range of key ultrasound parameters for the maximum stimulation in clinical applications. We have also suggested potential mechanisms of ultrasound-mediated enhancement of osteoblast proliferation to be investigated in future research.

\section{Appendix}

Intensity measures of pulsed ultrasound

We used an experimental setup shown in Figure 6a for measuring ultrasound intensities. The acoustic pressure was measured through the voltage signal, $V$ received by a 0.4-mm needle hydrophone (PZT-Z44-0400, Onda 
(a)

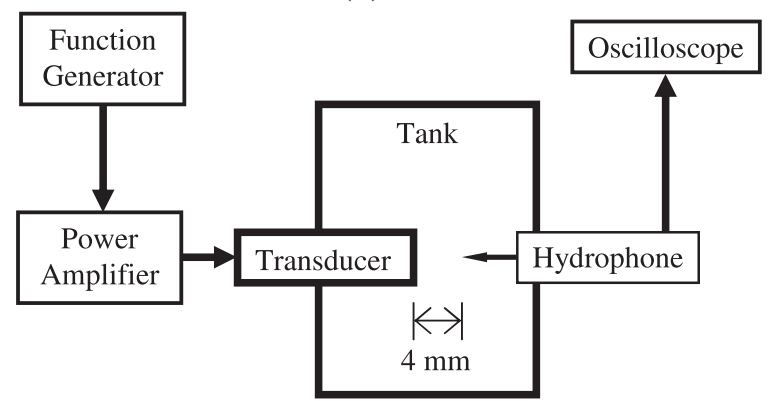

(b)

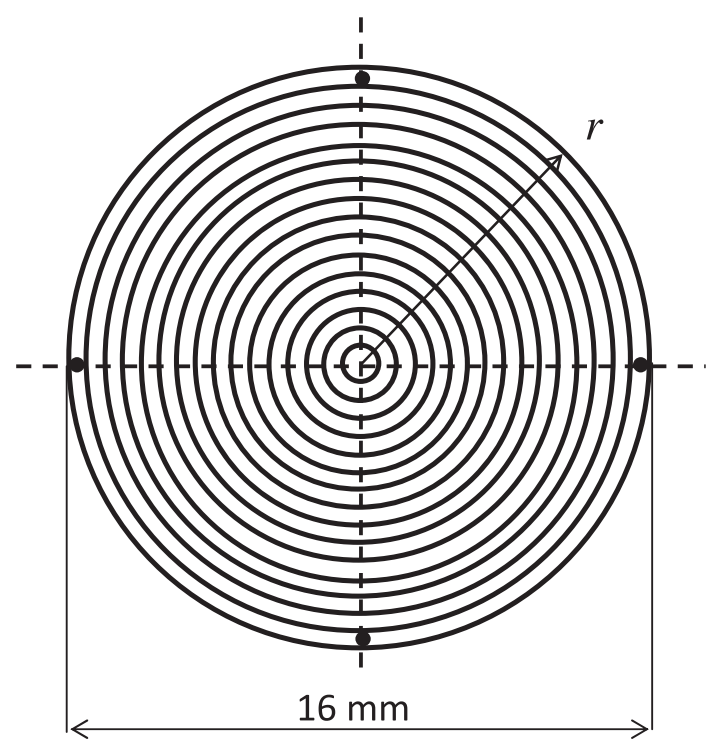

Figure 6 Setup to measure ultrasound intensity. (a) Experimental setup for ultrasound intensity measurement using hydrophone. (b) Schematic representation of the concentric annular regions and the innermost circular region in ultrasound beam for intensity measurement.

Corporation, CA, USA), and its free-field voltage sensitivity, $M$, as following:

$$
\text { pressure, } p(M \mathrm{~Pa})=1,000 \times \frac{V(m V)}{M\left(\frac{\mathrm{\mu V}}{\mathrm{Pa}}\right)} .
$$

The plane progressive wave approximation is assumed, so intensity is taken to be proportional to the square of the acoustic pressure. The temporal peak intensity, $I_{\mathrm{TP}}$ $(\boldsymbol{r})$, is related to maximum absolute pressure, $p_{m}(\boldsymbol{r})$, in the medium by the following expression:

$$
I_{T P}(\boldsymbol{r})=\frac{P_{m}(\boldsymbol{r})^{2}}{\rho c}
$$

where $r$ is the radial coordinate vector on focal surface $S, \rho$ is the medium density, and $c$ is the velocity of the sound in medium. $p_{\mathrm{m}}$ is half of the measured peakto-peak pressure at any position $\boldsymbol{r}$. The pulse average ultrasound intensity, $I_{P A}(\boldsymbol{r})$ and the temporal-average ultrasound intensity, $I_{T A}(\boldsymbol{r})$ were obtained as the following:

$$
\begin{aligned}
& I_{P A}(\boldsymbol{r})=\frac{1}{T_{P}} \int_{0}^{T_{p}} \frac{p(\boldsymbol{r}, t)^{2}}{\rho c} d t, \\
& I_{T A}(\boldsymbol{r})=I_{P A}(\boldsymbol{r}) \quad \text { duty cycle, }
\end{aligned}
$$

where duty cycle is the ratio of pulse duration $T_{P}$ and the pulse repetition period (inverse of pulse repetition frequency). For a sinusoidal input signal used in this work, $I_{P A}(r)$ reduces to

$$
I_{P A}(\boldsymbol{r})=\frac{P_{r m s}(\boldsymbol{r})^{2}}{\rho c}=\frac{P_{m}(\boldsymbol{r})^{2}}{2 \rho c} .
$$

The spatial-average temporal-average ultrasound intensity $\left(I_{S A T A}\right)$ and the spatial-average temporal-peak ultrasound intensity were obtained by averaging $I_{T A}(r)$ and $I_{T P}(\boldsymbol{r})$ respectively over the beam are as follows [42]:

$$
I_{S A T A}=\frac{1}{A_{26}} \int_{S_{26}} I_{T A}(\boldsymbol{r}) d S,
$$

and

$$
I_{S A T P}=\frac{1}{A_{26}} \int_{S_{26}} I_{T P}(\boldsymbol{r}) d S .
$$

where $S_{26}$ represents integration over the surface where the intensity is greater than $0.25 \%(-26 \mathrm{~dB})$ of the spatial peak intensity on $S$; and $A_{26}$ is the area of surface $S_{26}$ (i.e., $A_{26}$ is the $-26 \mathrm{~dB}$ beam area). The $-26-\mathrm{dB}$ figure is somewhat arbitrary; it is chosen to encompass essentially the entire ultrasound beam in the integration, yet remain above the hydrophone noise level. The spatial averaging for experimental measurement was performed in discrete manner for which the ultrasound beam was assumed to be composed of several concentric annular areas and the innermost circular area as shown in Figure 6b. On each annular area, four intensity measurements were obtained at points spacing $90^{\circ}$ from each other as shown in Figure $6 \mathrm{~b}$ and were averaged to represent the intensity in that annular area. Only one intensity value was measured at the innermost circular area. Thus, the integration in Equation 6 was computed as

$$
I_{S A T A}=\frac{1}{A_{\text {Transducer }}} \sum_{i} I_{T A_{i}} A_{i},
$$

where $A_{i}$ is the area of one of the discretized annular regions or the innermost circular region, $I_{T A i}$ is the respective average intensity, and $A_{\text {Transducer }}=\sum_{i} A_{i}$ is the 
area of the transducer face. Here we performed the spatial average over the transducer face area. The spatial average-pulse average intensity is defined as

$$
I_{S A P A}=\frac{I_{S A T A}}{\text { duty cycle }} \text {. }
$$

\section{Competing interests}

The authors declare that they have no competing interests.

\section{Authors' contributions}

AK designed the experiments, assembled the ultrasound exposure setup, developed the experimental protocols, conducted the experiments, collected, analyzed and interpreted the data, and drafted the manuscript. RLD and KS conceptualized the idea, supervised the research, analyzed and interpreted the data, and contributed to manuscript writing. All authors read and approved the final manuscript.

\section{Acknowledgements}

We would like to thank Drs. Weidong Yang and Joseph Gardinier for their scientific insight and advice during the course of these studies. We thank Krishna Nandan Kumar for his help with accessing the possibility of cavitation. RLD acknowledges partial support from NIH/NIAMS grants AR043222 and AR051901. KS acknowledges partial support from NSF grants no. CBET-0651912, CBET-1033256, DMR-1005283, and NIH grant no. P2ORR016472.

\section{Author details}

'Department of Mechanical Engineering, University of Delaware, Newark, DE 19716, USA. ${ }^{2}$ Department of Biological Sciences, University of Delaware, Newark, DE 19716, USA. ${ }^{3}$ Department of Mechanical and Aerospace Engineering, George Washington University, Washington, DC 20052, USA.

Received: 6 October 2013 Accepted: 3 December 2013

Published: 2 January 2014

\section{References}

1. Khan $Y$, Laurencin $C T$. Fracture repair with ultrasound: clinical and cell-based evaluation. J Bone Joint Surg Am. 2008; 90A:138-44.

2. Bishop GB, Einhorn TA. Current and future clinical applications of bone morphogenetic proteins in orthopaedic trauma surgery. Int Orthop. 2007; 31(6):721-7.

3. Frost HM. Wolff law and bones structural adaptations to mechanical usage - an overview for clinician. Angle Orthod. 1994; 64(3):175-88.

4. Woo SLY, Kuei SC, Amiel D, Gomez MA, Hayes WC, White FC, et al. The effect of prolonged physical-training on the properties of long-bone - a study of Wolffs law. J Bone Joint Surg Am. 1981; 63(5):780-7.

5. Takayama T, Suzuki N, lkeda K, Shimada T, Suzuki A, Maeno M, Akeson WH. Low-intensity pulsed ultrasound stimulates osteogenic differentiation in ROS 17/2.8 cells. Life Sci. 2007; 80(10):965-71.

6. Heybeli N, Yesildag A, Oyar O, Gulsoy UK, Tekinsoy MA, Mumcu EF. Diagnostic ultrasound treatment increases the bone fracture-healing rate in an internally fixed rat femoral osteotomy model. $J$ Ultrasound Med. 2002; 21(12):1357-63.

7. Warden SJ, Fuchs RK, Kessler CK, Avin KG, Cardinal RE, Stewart RL. Ultrasound produced by a conventional therapeutic ultrasound unit accelerates fracture repair. Phys Ther. 2006; 86(8):1118-27.

8. Mayr E, Frankel V, Ruter A. Ultrasound - an alternative healing method for nonunions? Arch Orthop Trauma Surg. 2000; 120(1-2):1-8.

9. Heckman JD, Ryaby JP, Mccabe J, Frey JJ, Kilcoyne RF. Acceleration of tibial fracture-healing by noninvasive, low-intensity pulsed ultrasound. I Bone Joint Surg Am. 1994; 76A(1):26-34.

10. Lubbert PHW, van der Rijt RHH, Hoorntje LE, van der Werken C. Low-intensity pulsed ultrasound (LIPUS) in fresh clavicle fractures: a multi-centre double blind randomised controlled trial. Inj-Int J Care Injured. 2008; 39(12):1444-52.

11. Gebauer D, Mayr E, Orthner E, Ryaby JP. Low-intensity pulsed ultrasound: effects on nonunions. Ultrasound Med Biol. 2005; 31(10):1391-402.

12. Baker KG, Robertson VJ, Duck FA. A review of therapeutic ultrasound: biophysical effects. Phys Ther. 2001; 81(7):1351-8.
13. Rubin C, Bolander M, Ryaby JP, Hadjiargyrou M. The use of low-intensity ultrasound to accelerate the healing of fractures. J Bone Joint Surg Am. 2001; 83A(2):259-70.

14. Claes $L$, Willie $B$. The enhancement of bone regeneration by ultrasound. Prog Biophys Mol Biol. 2007; 93(1-3):384-98.

15. Pounder NM, Harrison AJ. Low intensity pulsed ultrasound for fracture healing: a review of the clinical evidence and the associated biological mechanism of action. Ultrasonics. 2008; 48(4):330-8.

16. Li JKJ, Lin JCA, Liu HC, Sun JS, Ruaan RC, Shih C, Chang WH. Comparison of ultrasound and electromagnetic field effects on osteoblast growth. Ultrasound Med Biol. 2006; 32(5):769-75.

17. Kokubu T, Matsui N, Fujioka H, Tsunoda M, Mizuno K. Low intensity pulsed ultrasound exposure increases prostaglandin E-2 production via the induction of cyclooxygenase-2 mRNA in mouse osteoblasts. Biochem Biophys Res Commun. 1999; 256(2):284-7.

18. Ito M, Azuma $Y$, Ohta T, Komoriya K. Effects of ultrasound and 1,25-dihydroxyvitamin D-3 on growth factor secretion in co-cultures of osteoblasts and endothelial cells. Ultrasound Med Biol. 2000; 26(1):161-6.

19. Doan N, Reher P, Meghji S, Harris M. In vitro effects of therapeutic ultrasound on cell proliferation, protein synthesis, and cytokine production by human fibroblasts, osteoblasts, and monocytes. J Oral Maxillofac Surg. 1999; 57(4):409-19.

20. Hayton MJ, Dillon JP, Glynn D, Curran JM, Gallagher JA, Buckley KA. Involvement of adenosine 5 '-triphosphate in ultrasound-induced fracture repair. Ultrasound Med Biol. 2005; 31(8):1131-8.

21. Suzuki A, Takayama T, Suzuki N, Sato M, Fukuda T, Ito K. Daily low-intensity pulsed ultrasound-mediated osteogenic differentiation in rat osteoblasts. Acta Biochimica Et Biophysica Sinica. 2009; 41(2):108-15.

22. Kang KS, Lee SJ, Lee HS, Moon W, Cho DW. Effects of combined mechanical stimulation on the proliferation and differentiation of pre-osteoblasts. Exp Mol Med. 2011; 43(6):367-73.

23. Reher P, Elbeshir ENI, Harvey W, Meghii S, Harris M. The stimulation of bone formation in vitro by therapeutic ultrasound. Ultrasound Med Biol. 1997; 23(8):1251-8.

24. Li JGR, Chang WHS, Lin JCA, Sun JS. Optimum intensities of ultrasound for PGE(2) secretion and growth of osteoblasts. Ultrasound Med Biol. 2002: 28(5):683-90.

25. Park H, Yip MC, Chertok B, Kost J, Kobler JB, Langer R, Zeitels SM. Indirect low-intensity ultrasonic stimulation for tissue engineering. J Tissue Eng. 2010; 2010:973530.

26. Reher $P$, Harris M, Whiteman M, Hai HK, Meghii S. Ultrasound stimulates nitric oxide and prostaglandin E2 production by human osteoblasts. Bone. 2002; 31(1):236.

27. Parvizi J, Parpura V, Greenleaf JF, Bolander ME. Calcium signaling is required for ultrasound-stimulated aggrecan synthesis by rat chondrocytes. $J$ Orthop Res. 2002; 20(1):51.

28. Hillam RA, Skerry TM. Inhibition of bone-resorption and stimulation of formation by mechanical loading of the modeling rat ulna in vivo. $J$ Bone Miner Res. 1995; 10(5):683-9.

29. Bikle DD, Halloran BP. The response of bone to unloading. J Bone Miner Metab. 1999; 17(4):233-44.

30. Kapur S, Baylink DJ, Lau KHW. Fluid flow shear stress stimulates human osteoblast proliferation and differentiation through multiple interacting and competing signal transduction pathways. Bone. 2003; 32(3):241-51.

31. Dyson M. Nonthermal cellular effects of ultrasound. Br J Cancer. 1982; 45:165-71.

32. Tsai $\mathrm{CL}$, Chang WH, Liu TK. Preliminary studies of duration and intensity of ultrasonic treatments on fracture repair. Chin J Physiol. 1992; 35(1):21-6.

33. Robling $A G$, Hinant FM, Burr DB, Turner $\mathrm{CH}$. Shorter, more frequent mechanical loading sessions enhance bone mass. Med Sci Sports Exerc. 2002; 34(2):196-202.

34. Angle SR, Sena K, Sumner DR, Virdi AS. Osteogenic differentiation of rat bone marrow stromal cells by various intensities of low-intensity pulsed ultrasound. Ultrasonics. 2011; 51(3):281-8.

35. Appleford MR, Oh S, Cole JA, Protivínský J, Ong JL. Ultrasound effect on osteoblast precursor cells in trabecular calcium phosphate scaffolds. Biomaterials. 2007; 28(32):4788-94.

36. de GusmÃ fo C, Pauli J, Saad M, Alves J, Belangero W. Low-intensity ultrasound increases FAK, ERK-1/2, and IRS-1 expression of intact rat bones in a noncumulative manner. Clin Orthop Relat Res. 2010; 468(4):1149-56. 
37. Watabe H, Furuhama T, Tani-Ishii N, Mikuni-Takagaki Y. Mechanotransduction activates a $5 \beta 1$ integrin and PI3K/Akt signaling pathways in mandibular osteoblasts. Exp Cell Res. 2011; 317(18):2642-9.

38. Burnstock $G$, Verkhratsky A. Long-term (trophic) purinergic signalling: purinoceptors control cell proliferation, differentiation and death. Cell Death Dis. 2010; 1:1-10.

39. Genetos DC, Geist DJ, Liu D, Donahue HJ, Duncan RL. Fluid shear-induced ATP secretion mediates prostaglandin release in MC3T3-E1 osteoblasts. J Bone Miner Res. 2005; 20(1):41-9.

40. Gardinier JD, Majumdar S, Duncan RL, Wang L. Cyclic hydraulic pressure and fluid flow differentially modulate cytoskeleton re-organization in MC3T3 osteoblasts. Cell Mol Bioeng. 2009; 2(1):133-43.

41. Li J, Liu D, Ke HZ, Duncan RL, Turner CH. The P2X7 nucleotide receptor mediates skeletal mechanotransduction. J Biol Chem. 2005; 280(52):42952-9.

42. Kremkau FW. Diagnostic Ultrasound: Principles and Instruments. 7th ed. Philadelphia: W.B. Saunders Elsevier; 2006.

doi:10.1186/2050-5736-2-1

Cite this article as: Katiyar et al:: Ultrasound stimulation increases proliferation of MC3T3-E1 preosteoblast-like cells. Journal of Therapeutic Ultrasound 2014 2:1.

\section{Submit your next manuscript to BioMed Central and take full advantage of:}

- Convenient online submission

- Thorough peer review

- No space constraints or color figure charges

- Immediate publication on acceptance

- Inclusion in PubMed, CAS, Scopus and Google Scholar

- Research which is freely available for redistribution 